$$
\text { Artigos }
$$





\section{Por uma ciência e epistemologia(s) feminista(s): avanços, dilemas e desafios}

\section{By a feminist sciencenand epistemology advances, dilemmas and challenges}

\author{
Antonio Carlos Lima da Conceição* \\ Universidade Federal da Bahia \\ Lina M.Brandão de Aras** \\ Universidade Federal da Bahia
}

Resumo: Este artigo discute alguns desafios que se colocam ao processo de construção de teorias, em particular, à elaboração de teorias feministas. Pretende identificar e analisar, os avanços e desencontros do campo das mulheres nas ciências, discutindo os principais posicionamentos para a construção de uma epistemologia feminista e a sua importância para os estudos feministas nas ciências sociais e humanas.

Palavras-chave: Ciência. Feminismo. Epistemologia feminista.

Abstract: This article discusses some challenges in the process of building theories, in particular, the development of feminist theories. Aims to identify and analyze the progress and failures of the field of women in science, discussing the arguments for building a feminist epistemology and its importance to feminist scholarship in the social sciences and humanities. Keywords: Scien. Feminism. Feminist epistemology.

Nos últimos anos a situação das mulheres na ciência se constituiu em uma temática de certa autonomia no debate geral acerca do estado da ciência e da tecnologia no mundo contemporâneo. Podem ser estabelecidos antecedentes significativos entre esse novo status político da questão da mulher na ciência - os estudos acadêmicos sobre as relações entre ciência, tecnologia e sociedade - e os movimentos feministas.

Desde a "segunda onda do feminismo", ocorrida entre as décadas de 60 e 70 - que coincide, por sua vez, com um momento-chave na história da luta das mulheres por acesso ao conhecimento (KELLER,1996), multiplicaram-se os estudos que vinculam as mulheres aos processos da ciência e da tecnologia na sociedade, que em grande medida tem incorporado um enfoque de "gênero", conceito que planeja uma redefinição teórica e política com respeito ao conceito de sexo. Desde então, podem ser reconhecidos eixos problemáticos marcantes que orientam a reflexão sobre a mulher nesse campo.

\footnotetext{
* Bacharel em Direito

- UFBA, Licenciado em História - UCSAL, Mestre em Estudos Interdisciplinares sobre Mulheres, Gênero e Feminismo - PPG/NEIM-UFBA e Doutorando PPG/ NEIM - UFBA. E-mail: <curalima@ gmail.com>

** Doutora em História pela USP e professora do Programa de PósGraduação em Estudos Interdisciplinares sobre Mulheres, Gênero e Feminismo/UFBA. E-mail: <laras@ufba.br>
} 
Segundo SARDENBERG ( 2007, p.3), as feministas da Segunda Onda se depararam com o viés androcêntrico que tem permeado as teorias tradicionais, manifesto tanto na total exclusão ou invisibilidade do "feminino" quanto na forma (distorcida) em que as mulheres e seu universo são representados. Mas, as tentativas de incluir as mulheres e os temas relativos ao cotidiano feminino como objetos legítimos de investigação se forjavam, ainda, nos anos 70, com base nos mesmos conceitos, esquemas e métodos das teorias tradicionais - isto é, dentro dos próprios esquemas das problemáticas patriarcais de legitimar as mulheres como objeto de investigação científica, a sua legitimidade enquanto sujeitos do conhecimento, a autoridade epistêmica - e se debatia com a questão da objetividade e "neutralidade" científicas.

As pensadoras feministas vêm de há muito colocando em questionamento os parâmetros científicos definidores de quem pode ou não ser sujeito do conhecimento, do que pode consistir como conhecimento, ou mesmo o que pode ser conhecido. Um deles situa-se no segmento que tem sido chamado de "a questão da mulher na ciência”, e que se refere à sua participação nas atividades científicas e tecnológicas, em particular na pesquisa, e aos problemas do acesso à carreira profissional respectiva. Desse ponto de vista, problematiza-se a questão da “igualdade”, aparentada claramente com o processo mais amplo de reivindicação dos direitos à igualdade das mulheres em todas as ordens da vida social. $\mathrm{O}$ caso do direito à igualdade na ciência e na tecnologia se traduz como igualdade no acesso à educação e em particular à educação superior; no ingresso na carreira científica e seu desempenho posterior; no acesso a instâncias de decisão no desenvolvimento da ciência e da tecnologia na sociedade.

Outro eixo central tem-se constituído em torno de uma problematização de natureza epistemológica que, baseando-se na ideia da constituição social do conhecimento científico, concentra-se na análise da natureza revolucionária do olhar feminino sobre o mundo e, portanto, no potencial inovador da pesquisa científica gerada por mulheres. Dessa perspectiva, o problema não consiste tanto no melhoramento da participação das mulheres no sistema da ciência, senão nos esquemas interpretativos que dominam a construção simbólica da natureza e da sociedade.

O conhecimento produzido sobre e pelas mulheres sempre foi visto como de menor valor por versar sobre assuntos tidos como não afeitos ao rigor científico, nem dignos de serem contemplados pela ciência, como o cotidiano, as histórias de família, os gestos e os sonhos, enfim, temas considerados como “coisas de mulher”. Acrescem a essas críticas, voltadas para o tipo de objeto, outras que dizem respeito às atitudes das pesquisadoras, acusadas de não conseguirem agir com neutralidade, articulando teoria e prática de forma tão visceral a ponto de não separar a construção do conhecimento da militância. Isto faz com que, ainda hoje, quando é 
inegável a importância da pesquisa feminista no processo de reflexão sobre a sociedade, autores afirmem que "a contribuição feminista ainda não foi devidamente reconhecida no meio acadêmico, em particular por aqueles que insistem em manter uma postura formal em relação à ciência.

Esses, entre outros, são argumentos utilizados para dificultar a legitimidade do conhecimento feminista, deixando-o fora de muitas áreas do saber acadêmico, onde é visto com desprezo e desqualificação. Essas atitudes refletem os preconceitos que a sociedade tem com as atividades femininas e a falta de valor com que vê a mulher. Assim, mesmo sabendo-se que os estudos feministas são significativos em quantidade e qualidade, reiteradas afirmações indicam que "o conhecimento, seja sobre mulher seja sobre gênero, vem enfrentando dificuldades para obter reconhecimento como tema relevante para as ciências sociais.

As próprias pesquisadoras feministas concordam com algumas das críticas tecidas, em especial aquelas que as acusam de não separar teoria da prática, afirmando que isto faz parte do compromisso que têm com as mudanças sociais. Assim, a cada dia, conseguem abrir novos espaços na estrutura racionalista da academia, introduzindo novos temas de reflexão, assim como novas perspectivas teóricas e metodológicas. É indiscutível que essa flexibilização é uma forma de avanço para os estudos feministas, entretanto, os currículos acadêmicos continuam tratando a temática como marginal ou de menor importância.

As teóricas feministas têm a clara compreensão de que o conhecimento do mundo é socialmente construído e, dentro do mundo em que vivemos, determinado pelo gênero; pois, se este molda quem somos, também molda como pensamos e nossas concepções da ciência não podem se furtar a isso.

Jaggar e Bordo critica a ciência e questiona a concepção tradicional de que existe algo chamado natureza objetiva correspondendo a alguma realidade claramente discernível, que a mente humana pode compreender através do processo bastante simples e direto conhecido como razão. $\mathrm{O}$ método científico chegou a ser considerado como o veículo através do qual a mente, livre de fatores de classe ou status (religião, raça, nacionalidade, gênero) pode conhecer ou compreender essa realidade objetiva (Jaggar e Bordo In FARGANIS,1997, p.24).

Os autores citados ainda argumentam que se deve questionar o ideal cartesiano no qual se baseia a noção contemporânea da ciência, porque não leva em consideração o papel que a política e a história desempenham nessa busca etérea da verdade; além disso, não leva em conta as formas através das quais a razão, a emoção e a paixão significam coisas diversas e são avaliadas diferentemente por pessoas diferentes.

A epistemologia feminista contemporânea faz parte da crítica corrente ao modelo cartesiano de ciência, distinguindo-se de outros desafios, 
por atribuir preconceitos ligados ao gênero tanto ao método científico como à tradição epistemológica ocidental da qual ele faz parte. A contestação feminista não é a de afirmar que as mulheres podem, tão bem quanto os homens, raciocinar ou "fazer" ciência tal como é praticada agora. Em vez disso, sua posição é de que as mulheres que reconhecem e aceitam os pressupostos feministas sobre o mundo praticarão ciência de modo diverso num mundo que legitime esses pressupostos: usarão uma metodologia diferente ou se basearão num conjunto diferente de práticas para observar e compreender o mundo à sua volta; serão conscientes da intencionalidade de seus estudos e dos usos que deles se farão.

Em relação às categorias de análises utilizadas no campo epistemológico feminista, é possível aprender a aceitar sua instabilidade, encontrar nelas a desejada reflexão teórica sobre determinados aspectos da realidade política em que vivemos e pensamos, usar as próprias instabilidades como recurso de pensamento e prática. Isto porque a vida social que é nosso objeto de estudo, dentro da qual se formam e se testam as categorias analíticas, está em fervilhante transformação. A razão, a força de vontade, a revisão dos dados, até mesmo a luta política, em nada poderá reduzir o ritmo das mudanças de uma maneira que encha de júbilo nossos feminismos. Não passa de delírio imaginar que o feminismo chegue a uma teoria perfeita, a um paradigma de "ciência normal” com pressupostos conceituais e metodológicos aceitos por todas as correntes. As categorias analíticas feministas devem ser instáveis, teorias coerentes e consistentes em um mundo instável e incoerente são obstáculos tanto ao conhecimento quanto às práticas sociais.

No tocante à investigação do lugar das mulheres na ciência, esfera legitimada da produção do conhecimento, revelou tanto a ampla extensão dos fundamentos binários dessa ciência quanto a invisibilidade das mulheres como sujeitos dela. Como objetos da ciência, as mulheres definidas não somente como diferentes dos homens, mas também como biologicamente inferiores e, entre outras coisas, inadequadas ao exercício do papel de cientista.

A crítica do pensamento tem frequentemente feito avançar o conhecimento com mais eficácia do que o seu estabelecimento. A crítica feminista à ciência aponta para uma área particularmente fértil em que as categorias do pensamento ocidental necessitam de revisão. Embora tais críticas tenham começado por indagações politicamente controvertidas, mas teoricamente inócuas, acerca da discriminação contra as mulheres na estrutura social da ciência, dos usos indevidos da tecnologia e do preconceito androcêntrico nas ciências sociais e na biologia, elas logo se avolumaram em interpelações das premissas mais fundamentais do pensamento ocidental moderno. E, com isso, as críticas implicitamente desafiam as construções teóricas em que as questões iniciais foram formuladas, e segundo as quais poderiam ser respondidas. 
Ao fazermos o exame da crítica feminista à ciência, devemos, portanto, refletir sobre tudo o que a ciência não faz, as razões das exclusões, como elas conformam a ciência precisamente através das ausências, quer sejam elas reconhecidas ou não. Não há dúvida de que a crítica feminista das ciências naturais e sociais identificou e descreveu uma ciência mal conduzida - isto é, uma ciência distorcida pela visão masculina preconcebida na elaboração da problemática, nas teorias, nos conceitos, nos métodos de investigação, nas observações e interpretações dos resultados.

A concepção de ciência iluminista explicitamente negava que as mulheres possuíssem a racionalidade e a capacidade de observação desapaixonada e objetiva exigidas pelo pensamento científico. As mulheres podiam ser objeto da razão e da observação masculinas, mas nunca seus sujeitos, jamais poderiam ser mentes humanas reflexivas e universalizantes. Somente os homens eram vistos como formuladores ideais de conhecimento; e entre eles, apenas os que pertenciam à classe, raça e cultura corretas eram vistos como detentores de capacidade inata para o raciocínio e a observação socialmente transcendentes. As finalidades e propósitos de tal ciência se revelaram tudo menos libertadoras.

O marxismo reformulou essa visão iluminista fazendo do proletariado, guiado pela teoria e pela luta de classes, o detentor do conhecimento por excelência, o único grupo capaz de usar a observação e a razão para apreender a verdadeira forma das relações sociais, inclusive as relações com a natureza.

\section{Por uma epistemologia feminista da ciência}

A crítica feminista à ciência e os estudos feministas da ciência desenvolvem a partir dos anos 70 um espírito crítico reflexivo voltado para todos os campos do conhecimento científico. Nesse período, a evidência de que a maioria dos cientistas são homens faz com que a crítica feminista à ciência hegemônica preocupe-se em construir modelos de ciência implicados.

A primeira tipologia dos modelos de crítica feminista à ciência foi efetuada por Harding, através do empirismo feminista, cujo ponto nodal de preocupação seria a discriminação e sub-representação das mulheres na ciência (HARDING,1996). A solução seria atrair mulheres para a investigação, em uma tentativa de aumentar a representação das mulheres na ciência. Essa linha de orientação tem sofrido questionamentos, uma vez que a sua operacionalização e o seu caráter político continua a funcionar dentro do paradigma da ciência tradicional, sem analisar a divisão teórico-metodológica do androcentrismo.

Nas palavras de Harding, o empirismo feminista implica que "o sexismo e o androcentrismo poderiam ser eliminados dos resultados da investigação se os cientistas simplesmente seguissem de forma mais 
rigorosa e cuidadosa os métodos existentes e as normas de pesquisa” (HARDING,1996).

Na perspectiva teórica do stand point, as mulheres cientistas são consideradas oprimidas pela comunidade científica. Na produção do conhecimento as mulheres cientistas, antes de serem cientistas, partiram de um determinado posicionamento na hierarquia social - classe, etnicidade, sexo, orientação sexual (NEVES E NOGUEIRA, 2005). Essa posicionalidade é lida de forma a ser integrada na investigação propriamente dita. Nessa perspectiva as mulheres evidenciam um privilégio epistêmico que adviria da sua própria condição feminina, o que as torna ideais para estudar as mulheres. Para as teóricas do stand point, o conhecimento é parcial, contextualizado e experiencial (HARAWAY,1991).

Para as perspectivistas, uma das formas de combater a opressão patriarcal instalada na ciência seria valorizar a experiência feminina e a necessidade de dar voz às mulheres. De acordo com Nogueira, as críticas a essas epistemologias, dizem respeito ao essencialismo e ao diferencialismo que defendem, por basearem-se num privilégio epistemológico da condição feminina (NOGUEIRA, 2001).

A corrente de pensamento feminista pós-moderna vai buscar no movimento feminista pós-moderno e pós-estruturalista as suas principais referências. Essa linha crítica centra-se na construção genderizada do projeto de ciência moderna. Rejeita as propostas a-política do empiricismo feminista e o essencialismo e diferencialismo do stand point.

O projeto teórico-político ideológico pós-moderno feminista problematiza a própria ideia das mulheres enquanto categoria ontológica. Para as teóricas pós-modernas a categoria mulheres ilude as divisões intracategorias.

Segundo Haraway,

Com o reconhecimento arduamente conquistado, da sua constituição histórica social, o gênero, a raça e a classe não podem constituir a base para a crença na unidade 'essencial'. Não existe nada no fato de ser 'fêmea' que vincule naturalmente as mulheres. Não existe sequer o estado de ser 'fêmea', uma categoria em si mesma altamente complexa, construída em conturbados discursos científicos e outras práticas sociais.

Há uma relação tensa entre feminismo e pós-modernismo, pois o caráter relativista e a sua crítica a metanarrativas de legitimação põem em causa o próprio movimento, dado que desconstrói a mulher enquanto seu sujeito histórico. Nesse ponto, Haraway desenvolve a sua crítica às epistemologias tradicionais da ciência; para tanto, recorre, para além da reflexão epistemológica feminista, às perspectivas construcionistas dos estudos sociais da ciência e tecnologia. Ainda sustenta que os padrões tradicionais do método científico e da objetividade não são uma descrição adequada do modo como a ciência é feita (HARAWAY, 1991). 
Os conhecimentos situados são a proposta epistemológica de localização e de consideração da contextualidade do conhecimento no quadro da sua produção. Para essa perspectiva, o conhecimento tem um ponto de partida e de produção. A objetividade na produção científica assenta-se na parcialidade, no olhar contextualizado, o que vai de encontro aos falsos universalismos da ciência positiva vinculada à metanarrativa moderna patriarcal que busca verdades para legitimar-se.

Para esta corrente epistemológica, não há separação entre sujeito e objeto e a própria constituição do sujeito que conhece não é unificada. As múltiplas subjetividades são localizadas, construídas. De modo que não é a identidade que estrutura a posição do investigador, mas sim a afinidade parcial. A objetividade, portanto, reside na contextualização do conhecimento.

De acordo com Sandenberg,

A crítica feminista, instrumentalizada por um olhar desconstrucionista de gênero, tem avançado da mera denúncia da exclusão e invisibilidade das mulheres no mundo da ciência para o questionamento dos próprios pressupostos básicos da Ciência Moderna, virando-a de cabeça para baixo ao revelar que ela não é nem nunca foi “neutra”.

As divergências e embates no que se refere aos níveis da crítica que se faz à ciência e, quanto às estratégias epistemológicas que melhor poderão fundamentar e instrumentar a produção de um saber feminista, apresenta-se da seguinte forma: o que torna esse saber especificamente feminista? Para construí-lo, basta apenas denunciar e combater o androcentrismo na "má ciência”? Ou será que, de fato, só um saber fundamentado no ponto de vista das mulheres poderá levar adiante uma prática científica emancipatória para todas e todos? Mas, não seriam essas estratégias também “suspeitas”, dadas as “ (...) suas lealdades com os princípios do Iluminismo implícitos nesses projetos científicos e epistemológicos”(...)? (HARDING, 1991, p.7).

É possível uma epistemologia feminista da ciência mesmo com os problemas decorrentes do privilegiamento de um outro sujeito universal: a mulher.

A teorização feminista desenvolveu-se a partir da necessidade de uma forma de produção acadêmica que problematizasse as relações entre os sexos, mais do que produzisse análises a partir do privilegiamento do sujeito. Existiria uma maneira feminina de fazer ciência radicalmente diferente da masculina? No campo teórico feminista há um entendimento de que as mulheres tem um modo de interrogação próprio do olhar feminino, um ponto de vista específico ao abordar o objeto. 


\section{Pontos de reflexão para construção de "uma epistemologia feminista”}

Segundo Rago, no Brasil, "é visível que não há nem clarezas, nem certezas em relação a uma teoria feminista do conhecimento" (RAGO,1998, p.2). Afinal, se considerarmos que a epistemologia define um campo e uma forma de produção do conhecimento, o campo conceitual a partir do qual operamos ao produzir o conhecimento científico, a maneira pela qual estabelecemos a relação sujeito objeto do conhecimento e a própria representação de conhecimento como verdade com que operamos, deveríamos prestar atenção ao movimento de constituição de uma (ou seriam várias?) epistemologia feminista, ou de um projeto feminista de ciência.

O feminismo não apenas tem produzido uma crítica contundente ao modo dominante de produção do conhecimento científico como também propõe um modo alternativo de operação e articulação nesta esfera. Além disso, se consideramos que as mulheres trazem uma experiência histórica e cultural diferenciada da masculina, ao menos até o presente, uma experiência que várias já classificaram como das margens, da construção miúda, da gestão do detalhe, que se expressa na busca de uma nova linguagem, ou na produção de um contradiscurso, é inegável que uma profunda mutação vem se processando também na produção do conhecimento científico.

A questão se torna mais complexa, uma vez que há outras correntes vanguardistas do pensamento contemporâneo atuando no sentido das profundas desestabilizações e rupturas teóricas e práticas em curso. Além do mais, seria ingênuo considerar que a teoria feminista rompe absolutamente com os modelos de conhecimento dominantes nas Ciências Humanas, sem reconhecer que, se há rupturas, há também muitas permanências em relação à tradição científica.

Ainda de acordo com Rago, considerando a existência de uma/ várias epistemologia/s feminista/s, valeria então destacarmos, de início, dois pontos: o primeiro aponta para a participação do feminismo na ampla crítica cultural, teórica, epistemológica em curso, ao lado da Psicanálise, da Hermenêutica, da Teoria Crítica Marxista, do desconstrutivismo e do Pós-modernismo (RAGO,1998, p.2).

Esta crítica revela o caráter particular de categorias dominantes, que se apresentam como universais; propõe a crítica da racionalidade burguesa, ocidental, marxista incluso, que não se pensa em sua dimensão sexualizada, enquanto criação masculina, logo excludente. Portanto, denuncia uma racionalidade que opera num campo ensimesmado, isto é, a partir da lógica da identidade e que não dá conta de pensar a diferença. É neste ponto que o feminismo se encontra especialmente com o pensamento pós-moderno, com a crítica do sujeito, com as formulações de Derrida e Foucault, entre outras. $\mathrm{O}$ segundo, embutido no primeiro, traz as propostas desta nova 
forma de conceber a produção do conhecimento, do projeto feminista de ciência alternativa, que se quer potencialmente emancipador.

É necessário reafirmar que os principais pontos da crítica feminista à ciência incidem na denúncia de seu caráter particularista, ideológico, racista e sexista: o saber ocidental opera no interior da lógica da identidade, valendo-se de categorias reflexivas, incapazes de pensar a diferença. Em outras palavras, atacam as feministas: os conceitos com que trabalham as Ciências Humanas são identitários e, portanto, excludentes. Pensa-se a partir de um conceito universal de homem, que remete ao branco-heterossexual civilizado-do-Primeiro-Mundo, deixando-se de lado todos aqueles que escapam deste modelo de referência. Da mesma forma, as práticas masculinas são mais valorizadas e hierarquizadas em relação às femininas, o mundo privado sendo considerado de menor importância frente à esfera pública, no imaginário ocidental.

Logo, as noções de objetividade e de neutralidade que garantiam a veracidade do conhecimento caem por terra, no mesmo movimento em que se denuncia o quanto os padrões de normatividade científica são impregnados por valores masculinos. Mais do que nunca, a crítica feminista evidencia as relações de poder constitutivas da produção dos saberes, como aponta, de outro lado, Michel Foucault (FOUCAULT,1986, p.54). Este questionara radicalmente as representações que orientavam a produção do conhecimento científico, tida como o ato de revelação da essência inerente à coisa, a partir do desvendamento do que se considerava a aparência enganosa e ideológica do fenômeno.

Do mesmo modo, as teóricas feministas propuseram não apenas que o sujeito deixasse de ser tomado como ponto de partida, mas que fosse considerado dinamicamente como efeito das determinações culturais, inserido em um campo de complexas relações sociais, sexuais e étnicas. Portanto, em se considerando os “estudos da mulher”, esta não deveria ser pensada como uma essência biológica pré-determinada, anterior à História, mas como uma identidade construída social e culturalmente no jogo das relações sociais e sexuais, pelas práticas disciplinadoras e pelos discursos/ saberes instituintes. Como se vê, a categoria do gênero encontrou aqui um terreno absolutamente favorável para ser abrigada, já que desnaturaliza as identidades sexuais e postula a dimensão relacional do movimento constitutivo das diferenças sexuais.

O pensamento feminista se constitui em uma arena de tensões onde se embatem posicionamentos plurais e polêmicos, quando não conflitantes. É claro que essa diversidade de olhares e de posturas certamente enriquece nossos discursos críticos sobre a sociedade e a ciência, como uma de suas expressões; contudo, as divergências entre feministas tornam impossível falar de "epistemologia feminista" no singular (SARDENBERG, 2007, p.11). 
Coforme Harding, “Não há um só conjunto de assertivas, além de algumas poucas generalizações, que podem ser chamadas de 'feministas' sem provocar controvérsia entre feministas” (HARDING,1991, p.6). Talvez a única assertiva epistemológica feminista que, de fato, encontre consenso seja a noção mais geral de “conhecimento situado”, isto é, de que o conhecimento reflete a perspectiva ou "posicionalidade” dos sujeitos cognoscentes, sendo gênero um dos fatores determinantes na sua constituição (ANDERSON, 2001).

É dificil falar de uma epistemologia feminista, sem tocar na discussão sobre os perigos da reafirmação do sujeito "mulher” e de todas as cargas constitutivas dessa identidade no imaginário social. Afinal, como já se observou exaustivamente, a questão das relações sexuais e da mulher especificamente nasce a partir das lutas pela emancipação deste sujeito antes definido como “sexo frágil”. É na luta pela visibilidade da “questão feminina”, pela conquista e ampliação dos seus direitos específicos, pelo fortalecimento da identidade da mulher, que nasce um contradiscurso feminista e que se constitui um campo feminista do conhecimento. É a partir de uma luta política que nasce uma linguagem feminista.

Como se de repente os efeitos se desviassem dos objetivos visados no ponto de partida: a categoria relacional do gênero desinveste a preocupação de fortalecimento da identidade mulher, ao contrário do que se visava inicialmente com um projeto alternativo de uma ciência feminista.

Esta é uma das principais dificuldades que emergem, ao se tentar conceitualizar o campo epistemológico em que se funda um conhecimento sobre as mulheres e, agora, sobre as relações de gênero. A categoria do gênero, já observou Joan Scott, não nasce no interior de um sistema de pensamento definido como o conceito de classes em relação ao marxismo. Embora seja apropriada como instrumento analítico extremamente útil, procede de um campo profundamente diverso daquele que tinha como horizonte a emancipação social de determinados setores sociais. Nessa linha de pensamento, LONGINO (1995, p.21) observa, ainda, que foi depois do desenvolvimento do pensamento feminista nas áreas da história, antropologia, teoria literária, psicologia e sociologia que se passou a pensar nos conceitos através dos quais se operava.

A reflexão filosófica foi posterior à prática teórica, isto significa que houve uma incorporação das questões feministas em diferentes campos da produção do conhecimento científico, de fora para dentro, como por exemplo, na psicanálise ou no campo marxista. Os temas da mulher e do gênero foram incorporados às questões colocadas pela historiografia marxista, sem ter nascido a partir dela, enfrentando, aliás, sérias dificuldades em seu interior. Sabemos como a questão das relações entre os sexos, a história da sexualidade e do corpo e as lutas políticas das mulheres foram secundarizadas no marxismo, tidas como secundárias em relação às questões da luta das classes. Do mesmo modo, a questão étnica e racial. 
Esta incorporação, portanto, não se deu sem maiores complicações. Porque a entrada dos temas feministas em campos epistemológicos masculinos provocou muitas desestabilizações e, mesmo, rupturas, a despeito das muitas permanências. Os conceitos se mostravam estreitos demais para pensar a diferença; aliás, conceitos como masculinos, muitas vezes misóginos, precisavam ser transformados, abandonados, questionados, refeitos. Isso remete ainda a uma outra questão: o que vem a ser uma epistemologia feminista? Para que necessitamos de uma nova ordem explicativa do mundo?

Para melhor controlar o pensamento e o mundo? Uma nova ordem das regras para trazer poder político a um setor que se sente excluído? Desse modo Harding pergunta, então, ao lado de muitas outras feministas, se não estaríamos correndo o risco de repor o tipo de relação poder-saber que tanto criticamos:"Como é que o feminismo pode redefinir totalmente a relação entre saber e poder, se ele está criando uma nova epistemologia, mais um conjunto de regras para controlar o pensamento?” (HARDING, 1993, p.19).

É possível contra-argumentar lembrando que não há como fugir ao fato de que todas as minorias relativamente organizadas, e não apenas as mulheres, estão reivindicando uma fatia do bolo da ciência e que nenhum dos grupos excluídos - negros, africanos, orientais, homossexuais, mulheres - com suas propostas de epistemologias alternativas - feminista, terceiro-mundista, homossexual, operária - pode hoje reivindicar um lugar de hegemonia absoluta na interpretação do mundo. Além disso, há que se reconhecer as dimensões positivas da quebra das concepções absolutizadoras, totalizadoras, que até recentemente poucos percebiam como autoritárias, impositivas e hierarquizantes. Não há dúvidas de que o modo feminista de pensar rompe com os modelos hierárquicos de funcionamento da ciência e com vários dos pressupostos da pesquisa científica. Se a crítica feminista deve "encontrar seu próprio assunto, seu próprio sistema, sua própria teoria e sua própria voz,” (SHOWALTER,1994, p.29), é possível dizer que as mulheres estão construindo uma linguagem nova, criando seu argumento a partir de suas próprias premissas.

Sem dúvida alguma, há um aporte feminino/ista específico, diferenciador, energizante, libertário, que rompe com um enquadramento conceitual normativo. Talvez daí mesmo a dificuldade de nomear o campo da epistemologia feminista.

Vejamos alguns aspectos desse aporte: o questionamento da produção do conhecimento entendida como processo racional e objetivo para se atingir a verdade pura e universal, e a busca de novos parâmetros da produção do conhecimento. Aponta, então, para a superação do conhecimento como um processo meramente racional: as mulheres incorporam a dimensão subjetiva, emotiva, intuitiva no processo do conhecimento, questionando a 
divisão corpo/mente, sentimento/razão. Ainda nessa linha de pensamento, "em busca de parâmetros conceituais e filosóficos alternativos, muitos pensadores abraçaram modos de análise que rejeitam a dicotomização entre razão e paixão, entre saber e sentimento” (LOMGINO,1995).

O pensamento feminista trouxe a subjetividade como forma de conhecimento, o que se opõe radicalmente ao ideal de conhecimento objetivo trazido das Ciências Naturais para as Ciências Humanas. Entrando num mundo masculino, possuído por outros, a mulher percebe que não detém a linguagem e luta por criar uma, ou ampliar a existente: aqui se encontra a principal fonte do aporte feminista à produção do conhecimento, à construção de novos significados na interpretação do mundo.

\section{Considerações finais}

O feminismo propõe uma nova relação entre teoria e prática. Delineia-se um novo agente epistêmico, não isolado do mundo, mas inserido no coração dele, não isento e imparcial, mas subjetivo e afirmando sua particularidade. Ao contrário do desligamento do cientista em relação ao seu objeto de conhecimento, o que permitiria produzir um conhecimento neutro, livre de interferências subjetivas, clama-se pelo envolvimento do sujeito com seu objeto.

Concordando com Sandra Harding: "Uma forma de resolver o dilema seria dizer que a ciência e a epistemologia feministas terão um valor próprio ao lado, e fazendo parte integrante, de outras ciências e epistemologias - jamais como superiores às outras.”

No caso dos estudos feministas, o sucesso da categoria do gênero se explica, em grande parte, por ter dado uma resposta interessante ao impasse teórico existente, quando se questionava a lógica da identidade e se decretava o eclipse do sujeito. Categoria relacional, como observa Joan Scott, encontrou campo extremamente favorável num momento de grande mudança das referências teóricas vigentes nas Ciências Humanas, e em que a dimensão da Cultura passava a ser privilegiada sobre as determinações da Sociedade.

Assim como outras correntes de pensamento, a teoria feminista propunha que se pensasse a construção cultural das diferenças sexuais, negando radicalmente o determinismo natural e biológico. Portanto, a dimensão simbólica, o imaginário social e a construção dos múltiplos sentidos e interpretações no interior de uma dada cultura passavam a ser priorizados em relação às explicações econômicas ou políticas.

Enfim, parece que já não há mais dúvidas de que as mulheres sabem inovar na reorganização dos espaços físicos, sociais, culturais e, podese complementar aqui, nos intelectuais e científicos. E o que me parece mais importante, sabem inovar libertariamente, abrindo o campo das 
possibilidades interpretativas, propondo múltiplos temas de investigação, formulando novas problematizações, incorporando inúmeros sujeitos sociais, construindo novas formas de pensar e viver.

\section{Referências}

BUTLER, Judith. Gender Trouble: Feminism and the Subversion of Identity. New York: Routledge, 1990.

FARGANIS, Sandra. O Feminismo e a reconstrução da ciência social. In: JAGGAR, Alisson M. \& BORDO, Susan R.(orgs.), Gênero, Corpo, Conhecimento. Rio de Janeiro: Record: Rosa dos Tempos,1997, pp.224240.

FOUCAULT, Michel. Arqueologia do saber. Rio de Janeiro: Forense Universitária, 1986, p.54

GROSZ, Elizabeth. Bodies and Knowledges: Feminism and the Crisis of Reason, in ALCOFF, L. e POTTER, E. , op. cit. p. 206.

HARAWAY, Donna. “Saberes Localizados: a questão da ciência para o feminismo e o privilégio da perspectiva parcial”. UNICAMP, Cadernos PAGU, n ${ }^{0}$ 5,1995, p.14.

HARDING, Sandra. The Science Question in Feminism. Ithaca: Cornell University Press, 1986.

. A instabilidade das Categorias Analíticas na Teoria Feminista”, in Revista de Estudos Feministas, vol.1, nº.1, Rio de Janeiro CIEC/ECO/ UFRJ. 1993, p.19.

. Ciência Y feminismos. Tradução de Pablo Manzano, Madrid: Edições Morato, S.L.,1996.

2004.

The Feminist Standpoint Theory Reader. New York: Routledge,

KELLER, Evelyn Fox. Feminism and science. In: KELLER, Evelyn Fox, and LONGINO, Helen (eds.). Feminism and Science. Oxford: Oxford University Press, 1996. pp.28-90.

LONGINO, Helen E. To See Feelingly: Reason, Passion, and Dialogue in Feminist Philosophy, in Donna C. Stanton e A. Stewart (org.) Feminisms in the academy, Ann Arbor: The University of Michigan Press,1995, p.21.

LYOTARD, Jean-François. A condição pós-moderna. Lisboa: Gradiva, 1989.

NOGUEIRA, Conceição. Um novo olhar sobre as relações sociais de género: perspectiva feminista crítica na psicologia social. 1996. Tese (Doutoramento em Psicologia Social) - Universidade do Minho, Braga. 
. Um novo olhar sobre as relações sociais de género: feminismo e perspectiva crítica na psicologia social. Lisboa: Fundação Gulbenkian, 2001.

RAGO, Margaret. Epistemologia Feminista, Gênero e história. In: PEDRO, Joana M. e GROSSI, Mirian P. (orgs), Masculino, Feminino, plural. Florianópolis, Editora das Mulheres,1998, pp.24-42.

SANTOS, Boaventura de Sousa. Um discurso sobre as ciências. Porto: Afrontamento, 1988.

SARDENBERG, Cecilia. Da Crítica Feminista à Ciência a uma Ciência Feminista? Labrys. Estudos Feministas , v. 11, 2007, p.45.

SHOWALTER, Elaine. A crítica feminista no território selvagem, in HOLLANDA, Heloísa Buarque de (org.) Tendências e Impasses. O Feminismo como Crítica da Cultura. Rio de Janeiro: Rocco,1994, p.29.

Recebido em: 07/03/2013

Aprovado em: 08/09/2013 